\title{
Habitat niche community-level analysis of an amphibian assemblage at Lake Nabugabo, Uganda
}

\author{
Mathias Behangana and Luca Luiselli
}

Behangana, M. and Luiselli, L. 2008. Habitat niche community-level analysis of an amphibian assemblage at Lake Nabugabo, Uganda. - Web Ecol. 8: 125-134.

\begin{abstract}
Community structure was studied across six different habitat types in an amphibian assemblage constituted by 24 species belonging to five families, from Lake Nabugabo, Uganda. We employed a suite of different statistical methods, including univariate, multivariate, and Monte Carlo procedures to investigate the randomness/nonrandomness and the seasonal effects (wet versus dry season) of the community assembly. We calculated for each species in each habitat type an index of relative abundance by using a time constrained counting technique, with 48 1-h counts for each habitat type. Co-occurrence was analysed by $\mathrm{C}$ score with 30000 simulations; resource partitioning patterns by RA2 and RA3 algorithms with 30000 simulations; and apparent dissimilarity among species in terms of habitat use by UPGMA dendrograms. After pooling data from wet and dry seasons, it resulted that the amphibian community was nonrandomly assembled according to C-score analyses, but both RA2 and RA3 were unable to uncover any competitive structure for the dataset. Seasonal effects were evident, and although $\mathrm{C}$ score analyses confirmed a nonrandom structure for the community under study (particularly in wet season), RA3 showed that species with high relative abundance tended to significantly concentrate in one habitat type (swamp forest) rather than to partition the habitat resource. UPGMA dendrograms grouped the species differently in dry versus wet seasons. Overall, the comparative evidence of 1) non-random community structure according to C-score analysis, and 2) absence of resource partitioning according to niche overlap null models analysis, suggests that community organization in Lake Nabugabo amphibians is generated by habitat affinities rather than by interspecific competition.
\end{abstract}

M. Behangana, Makerere Univ. Inst. of Environment and Natural Resource. PO Box 7298, Kampala, Uganda. - L. Luiselli (lucamlu@tin.it), Centre of Environmental Studies, Dementa and F.I.Z.V. (Ecology), via Olona 7, IT-00198 Rome, Italy.

As every mature science, also ecology has several fundamental principles, laws, and constituent theories (Lawton 1999, Turchin 2001, Scheiner and Willig 2007). Community ecology is based on the intersection of several constituent theories, out of which the niche theory is one of the more complete theories (Chase and Leibold 2003, Simberloff 2004). In part as a by-product of niche theory, it has been hypothesized that the strength of interspecific competition is not equally intense at all climates and lati- tudes, being generally stronger in equatorial and tropical than in non-tropical and temperate climates (Pianka 1966, Rohde 1992). When interspecific competition is strong, living communities should be characterized by a nonrandom 'structure' that can be uncovered by appropriate statistical procedures, e.g. the null models (Gotelli and Graves 1996, Gotelli 2000, Gotelli and McGill 2006). However, non-random structure does not necessarily have to result from competitive interactions, as it can be the result of 
strong species-environment relations, as well as underlying non-random spatial processes (Gotelli 2000, Gotelli and McGill 2006). In community ecology studies, 'structure' in a given assemblage of species is usually defined as the situation in which the various sympatric species partition the niche resource available in a mathematically predictable way, while a null model is a pattern-generating model that is based on randomisation of ecological data or random sampling from a known or specified distribution (Gotelli and Graves 1996, Gotelli and McGill 2006). Thus, a community structure should in theory be easier to uncover in equatorial and tropical than in temperate assemblages of species.

In recent meta-analyses of ectothermic vertebrate community assembly rules, Luiselli (2006a, 2008a) effectively statistically detected more cases of nonrandom structure among tropical communities of reptiles than among non-tropical ones, particularly with African communities (Luiselli 2008a). Meta-analyses of the same type are not yet available for amphibians, in part because the overall number of community ecology studies is in general reduced in amphibians compared to reptiles, but essentially because there are vast regions of the tropical and equatorial regions that are still unstudied with regards to amphibian community assembly rules (Toft 1985). Sub-Saharan Africa is traditionally among these neglected regions, although several studies have appeared in the recent years (Parris 2004, Ernst and Rödel 2005, 2006, 2008, Gardner et. al. 2007). Recent studies in the region of Lake Nabugabo, Uganda, however provided a valuable community ecology dataset for the amphibians of east Africa (Behangana and Arusi 2004). These studies furnished the basic dataset that is used also in the present paper.

Our aim in this paper is to analyze the community structure of an assemblage of amphibians from Uganda. This amphibian assemblage is moderately species-rich (24 species belonging to 5 families; Behangana and Arusi 2004) compared to amphibian communities in the Neotropics, sometimes exceeding 100 species (Duellmann 2005); but even by African standards if compared to some west and central African communities with well over 50 species (Rödel et al. 2004). Our emphasis is on answering to the following key-questions: 1 ) is there any detectable nonrandom structure in the amphibian assemblage under study? We will answer to this question by using a suite of univariate, multivariate, and Monte Carlo statistical procedures. 2) Given that equatorial and tropical climates are characterized by distinct alternating of dry and wet seasons, and given that seasonality has been demonstrated to influence community structure in seasonal environments (Ernst and Rödel 2005, 2006, 2008, Filippi and Luiselli 2007), is there a detectable seasonal effect on the community assembly rules of the amphibian assemblage under study? 3) If a non-random structure is detected in the study assemblage of species, should it depend on in- terspecific competition or on other reasons (e.g. habitat affinities, Gotelli and McCabe 2002)?

\section{Material and methods}

\section{Nomenclature of the study species}

Nomenclature and taxonomy of east African amphibians is still debated and far from being resolved (Schiotz 1999, Channing and Howell 2006, Pickersgill 2007). While waiting for someone to solve the puzzling taxonomy of African frogs, in this paper we generally used the nomenclature given by Channing and Howell (2006), with the following exceptions: Hylarana instead of Amnirana or Amietia, and Hyperolius nasutus sensu 'the nasutus group' in Schiotz (1999) and Pickersgill (2007).

\section{Study area and protocol}

The field study was conducted, by one of the authors (MB), in April to November 2002 at a study area at Lake Nabugabo, a small body of open water (about $24 \mathrm{~km}^{2}$ surface) lying within an extensive swamp on the western shores of Lake Victoria (Masaka District, Uganda; $0^{\circ} 20^{\prime} \mathrm{S}-0^{\circ} 25^{\prime} \mathrm{S}$, $31^{\circ} 50^{\prime}-31^{\circ} 56^{\prime} \mathrm{E} ; 1200 \mathrm{~m}$ a.s.l.). Full details of study area and field methods are detailed elsewhere (Behangana and Arusi 2004), and here we limit ourselves to give a short description of only the fundamental aspects. Except in some places of the western shore, the lake margin is predominantly swampy. The western shore is more varied, in some places, with gently sloping sandy beaches and in other places forest, reaching to the edge of the lake. The swamp margin begins with a zone of hippo grass Vossia cupsidata, whose rhizomes grow out into the open water. Behind the hippo grass is a high 'hedge' of Miscanthidium violaceum forming a floating platform of matted roots and rhizomes jutting into the lake. Away from the margin, this platform becomes more solid through the addition and incorporation of dead and decaying vegetation. In some places the platform though still afloat, is sufficiently compacted to support the growth of trees. The Miscanthidium violaceum zone is succeeded by much shorter vegetation. The dominant plant is Loudetia phragmitoides, its tussock habit allowing the development of small open pools. The main inflows into Lake Nabugabo are River Juma and the Lwamunda swamp. River Juma is covered predominantly by Cyperus papyrus. Patches of this vegetation type are also found along rivers feeding Lwamuda swamp. Other vegetation types close to the lake and influencing its ecosystem include swamp forest and medium altitude forest (forest savannah mosaic).

The study area consisted of a parcel of territory of about $2.5 \mathrm{~km}^{2}$, well representative of the mosaic of natural habi- 
tats found at Lake Nabugabo. Six different habitat types were available to amphibians at the study area: (A) vegetation on the shoreline about $2 \mathrm{~m}$ from the shoreline, composed of sandy beaches in some places with hardly any vegetation while in other parts it is composed of swamp margins dominated by hippo grass Vossia cupsidata; (B) Miscanthidium violaceum vegetation formation; (C) Eragrostis-Loudetia vegetation formation; (D) swamp forest; (E) Cyperus papyrus swamps; and (F) medium altitude evergreen forest.

Overall, 168 days were spent in the field, for a total of 288 1-h counts. In order to standardize the field effort across habitat types, the time constrained counting technique was employed (Bury and Corn 1991). Standardization of field effort across habitat types was assured by an equal number of 1 -h counts per habitat type (i.e. 48 counts in each vegetation type). For each species, an index of relative abundance (i.e. number of individuals per time of searching) was calculated in each habitat type during both dry and wet seasons. These indices provide a rather objective measure of relative population abundance of each species in each habitat type, although potential biases due to different catchability across habitats could not be excluded (Akani et al. 1999, Luiselli and Akani 2002). Frogs were caught, identified on spot and released, but if not identified, voucher specimens were collected (Behangana and Arusi 2004). Photographic records of the various individuals were also taken.

\section{Statistical analyses}

To test whether the amphibian community was structured or not, we contrasted the actual data matrix with data on random 'pseudo-communities 'generated by Monte Carlo simulations (Gotelli and Graves 1996). Co-occurrence of the various frog species in each survey period (wet season, dry season and both seasons pooled) was evaluated for non-random patterns in a presence-absence matrix (Gotelli and Graves 1996). We generated 30000 random matrices and used as a co-occurrence index the $\mathrm{C}$ score of Stone and Roberts (1990). The C score is the average of all possible checkerboard pairs, calculated for species that occur at least once in the matrix, and in a competitively structured community, the $\mathrm{C}$ score should be significantly larger than that expected by chance (Gotelli and Graves 1996).

For calculating the similarity in habitat resource types used by the various species, both in general and in relation to the seasons, we calculated the niche overlap index of Pianka (1973). We calculated this index using the program 'EcoSim 700'(Gotelli and Entsminger 2003). We used the equiprobable resource state assumption when calculating the niche overlap between species pairs (Gotelli and Graves 1996). It is, however, to be stressed that overlap formulae may have some still unexplored biases in their accuracy of a particular estimator, especially due to sample sizes, total number of different resources, and evenness of resource distribution (Smith and Zaret 1982). To assess whether the observed overlap values of the various species pairs occurred by chance, we randomised the original species utilization matrices by shuffling the original values amongst the resource states (randomization algorithms defined RA2 and RA3 by Lawlor 1980); for each pair, 30000 random Monte Carlo permutations were generated. This number of permutations is enough to avoid algorithm biases in calculations (Lehsten and Harmand 2006). Niche overlap values were calculated for each of these randomly generated matrices, and species-pair and community-summary statistics were computed (Friggens and Brown 2005). Actual overlap values were then compared with the distributions of the expected values. RA2 tests for structure in the generalist-specialist nature of the resource utilization matrix by conserving guild structure but destroying observed niche breadth; RA3 tests for guild structure by conserving niche breadth for each species but destroying guild structure manifested by the zero structure of the resource utilization matrix (Gotelli and Graves 1996). A community structure compatible with the occurrence of interspecific competition in the species assemblage under study was assumed when $\mathrm{p}_{\text {obsexp }}=0.05$ or less either with RA 2 or RA3, whereas a significant concentration of species, e.g. for the presence an unlimited resource, was assumed when $\mathrm{p}_{\text {obs exp }}$ $=0.05$ or less (Gotelli and Graves 1996).

Statistics were calculated, all tests being two-tailed and with alpha set at 5\%, using the Statistica ver. 7.0 and SPSS ver. 11.0.4 packages, and Monte Carlo simulations were conducted using the EcoSim package (Gotelli and Entsminger 2003). Variations between seasons in the relative abundance of the various amphibian species in each habitat type were tested by paired t-test, with the first sample being the dry season, and the second sample being the wet season, and with each species being a different case. Dissimilarity among species in terms of habitat types used, during both dry and wet seasons, was visualized by UPGMA (unweighed pair-group method using arithmetic averages) dendrograms, applied to presence-absence of species on a matrix of Euclidean distances (Sneath and Sokal 1973, Digby and Kempton 1987).

\section{Results}

\section{Overall analysis}

Data summarizing the relative abundance of the species are given in Table 1. Overall, 24 different species were sampled at the study area (Behangana and Arusi 2004), but of these 23 were sampled during the wet season and 21 during the dry season. If we pool data from both dry and wet seasons, C-score analyses revealed that the amphib- 
Table 1. Relative abundance of the amphibian species at the study area, by habitat type. Data are presented with wet and dry seasons cumulated (A), only wet season (B), and only dry season (C).

Species

(A)

Afrixalus fulvovittatus

Bufo regularis

Bufo steindachneri

Bufo vittatus

Hylarana albolabris

Hylarana galamensis

Hyperolius bayoni

Hyperolius kivuensis

Hyperolius cinnamomeoventris

Hyperolius nasutus

Hyperolius viridiflavus

Kassina senegalensis

Leptopelis bocagii

Phrynobatrachus graueri

Phrynobatrachus natalensis

Phrynobatrachus acridoides

Phrynobatrachus dendrobates

Ptychadena anchietae

Ptychadena mascareniensis

Ptychadena porosissima

Ptychadena oxyrhynchus

Afrana angolensis

Hoplobatrachus occipitalis

Xenopus laevis

(B)

Afrixalus fulvovittatus

Bufo regularis

Bufo steindachneri

Hylarana albolabris

Hylarana galamensis

Hyperolius bayoni

Hyperolius kivuensis

Hyperolius cinnamomeoventris

Hyperolius nasutus

Hyperolius viridiflavus

Kassina senegalensis

Leptopelis bocagii

Phrynobatrachus graueri

Phrynobatrachus natalensis

Phrynobatrachus acridoides

Phrynobatrachus dendrobates

Ptychadena anchietae

Ptychadena mascareniensis

Ptychadena porosissima
11.54

4.07

3.71

0

3.5

0

13

12.79

5.93

14.64

0

0

0

0

0

0

0

0

0

2.86

0

0

0

0.57

15.25

4.75

5

4.5

0

16.5

17

8.25

20

0

0

0

0

0

0

0

0

0

4
Habitat types

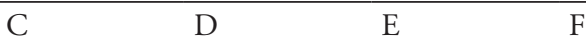

$\begin{array}{llll}4.46 & 35.54 & 0 & 0 \\ 0.86 & 0 & 0 & 0 \\ 0 & 0 & 0 & 0 \\ 0 & 0 & 0 & 0 \\ 0 & 5 & 6.7 & 0 \\ 1.79 & 1.64 & 0 & 0 \\ 8.93 & 37.71 & 22.93 & 3.86 \\ 3.93 & 64.64 & 16.29 & 3.57 \\ 0 & 37.36 & 5.86 & 0 \\ 28.86 & 37.36 & 5.86 & 0 \\ 5.21 & 33.71 & 0 & 0 \\ 4.86 & 0 & 0 & 0 \\ 0 & 0.07 & 0 & 0.79 \\ 14.79 & 6.14 & 0 & 1.07 \\ 4.86 & 6.14 & 0 & 0 \\ 1.21 & 0 & 0 & 0 \\ 2.21 & 0 & 0 & 0 \\ 0 & 0 & 0 & 3 \\ 10.71 & 0 & 4.29 & 0 \\ 0 & 0 & 0 & 0 \\ 1.5 & 0 & 0 & 0 \\ 1.93 & 5.14 & 0 & 0 \\ 11.79 & 14.29 & 2.57 & 0 \\ 0 & 0 & 0 & \end{array}$

\section{5}

0

43.5

0

0

5

2.25

42.5

84.5

44.5

40.25

62.5

11

10.25

0

37

0

0.25

26.75

1

2.5

4.25

0

16

0
8

9.5

0

0

0

0

0

$\begin{array}{ll}0 & 0 \\ 0 & 0 \\ 0 & 0 \\ 6.75 & 0 \\ 0 & 0 \\ 18 & 3.5 \\ 12 & 2.75 \\ 9.75 & 0 \\ 4.75 & 0 \\ 0 & 0 \\ 0 & 0 \\ 0 & 1.75 \\ 0 & 0.5 \\ 0 & 0 \\ 0 & 0 \\ 0 & 0 \\ 0 & 2.5 \\ 6.5 & 0 \\ 0 & 0\end{array}$




\begin{tabular}{|c|c|c|c|c|c|c|}
\hline Ptychadena oxyrhynchus & 0 & 0 & 2.5 & 0 & 0 & 0 \\
\hline Afrana angolensis & 0 & 0.75 & 4.5 & 6.25 & 0 & 0 \\
\hline Hoplobatrachus occipitalis & 0 & 8.5 & 16.25 & 12.25 & 5.25 & 0 \\
\hline Xenopus laevis & 1.25 & 0 & 0 & 0 & 0 & 0 \\
\hline \multicolumn{7}{|l|}{ (C) } \\
\hline Afrixalus fulvovittatus & 7.75 & 0 & 0.75 & 26.5 & 0 & 0 \\
\hline Bufo regularis & 3.75 & 0 & 2 & 0 & 0 & 0 \\
\hline Bufo steindachneri & 3 & 0 & 0 & 0 & 0 & 0 \\
\hline Bufo vittatus & 0 & 0 & 0.5 & 0 & 0 & 0 \\
\hline Hylarana albolabris & 2.5 & 1 & 0 & 4.5 & 6.75 & 0 \\
\hline Hylarana galamensis & 0 & 2 & 0.5 & 1.5 & 0 & 0 \\
\hline Hyperolius bayoni & 10.25 & 24.25 & 0 & 31 & 27.75 & 4.5 \\
\hline Hyperolius kivuensis & 9 & 25.75 & 0.75 & 43.5 & 21.25 & 5 \\
\hline Hyperolius cinnamomeoventris & 3.75 & 5.5 & 0 & 28.75 & 10.5 & 3.5 \\
\hline Hyperolius nasutus & 9.75 & 40.75 & 0 & 31.25 & 7 & 0.5 \\
\hline Hyperolius viridiflavus & 0 & 23 & 0.75 & 1.5 & 0 & 0 \\
\hline Phrynobatrachus graueri & 0 & 1.25 & 2.25 & 5 & 0 & 2.25 \\
\hline Phrynobatrachus natalensis & 0 & 0 & 0 & 3.5 & 0 & 0 \\
\hline Phrynobatrachus acridoides & 0 & 0 & 0.5 & 0 & 0 & 0 \\
\hline Phrynobatrachus dendrobates & 0 & 0 & 0.5 & 0 & 0 & 0 \\
\hline Ptychadena anchietae & 0 & 0 & 0 & 0 & 0 & 3.75 \\
\hline Ptychadena mascareniensis & 0 & 0 & 5.25 & 0 & 1.25 & 0 \\
\hline Ptychadena porosissima & 4 & 0 & 2.25 & 0 & 0 & 0 \\
\hline Ptychadena oxyrhynchus & 0 & 0 & 0.5 & 0 & 0 & 0 \\
\hline Afrana angolensis & 0 & 4.25 & 0 & 4.25 & 0 & 0 \\
\hline Hoplobatrachus occipitalis & 0 & 6 & 8.75 & 6.75 & 2.25 & 0 \\
\hline
\end{tabular}

ian community was non-randomly assembled (observed index $=1.005$, mean of simulated indices $=0.854$, variance of simulated indices $=0.0011, \mathrm{p}_{\mathrm{obs}<\exp }=0.999, \mathrm{p}_{\mathrm{obs}>\exp }$ $=0.001$ ).

However, both RA2 and RA3 algorithms indicated that the various species in the community did not partition the spatial (= habitat type) resource in a non-random way when data are pooled from wet and dry seasons (mean niche overlap value $=0.351$, observed variance $=0.126$; RA2 - mean of simulated indices $=0.367$, mean of simulated variances $=0.108$, variance of simulated indices $=$ 0.00042 , variance of simulated variances $=0.00004, \mathrm{p}_{\text {obscexp }}$ $=0.995, \mathrm{p}_{\text {obs }>\exp }=0.005 ; \mathrm{RA} 3-$ mean of simulated indices $=0.300$, mean of simulated variances $=0.108$, variance of simulated indices $=0.00035$, variance of simulated variances $\left.=0.00004, \mathrm{p}_{\text {obs } \exp }=0.997, \mathrm{p}_{\text {obs }>\exp }=0.003\right)$.

\section{Seasonal analysis}

UPGMA dendrograms based on interseasonal dissimilarity among species presence-absences among habitat types (Fig. 1) showed that, during the wet season habitats A, $\mathrm{E}$, and $\mathrm{F}$ were clearly clustered together, whereas during the dry season the closest cluster was between $\mathrm{A}, \mathrm{C}$, and
F. Paired t-tests confirmed the occurrence of interseasonal differences in community characteristics: the relative abundance of the species was significantly higher during the wet season than in dry season in three habitat types, i.e. A, C, and D (Table 2). Because of these apparent differences that occurred in the amphibian community between seasons, we analysed separately samples from wet and dry seasons with null models.

\section{Co-occurrence analysis}

In the wet season, C-score analyses revealed a non-random community structure, well compatible with a competitively structured assemblage (observed index $=1.087$, mean of simulated indices $=1.025$, variance of simulated indices $=$ $\left.0.0009, \mathrm{p}_{\text {obscexp }}=0.965, \mathrm{p}_{\text {obs }>\exp }=0.043\right)$. The same nonrandom structure was also evidenced, and even reinforced, during the dry season (observed index $=1.405$; mean of simulated indices $=1.219$, variance of simulated indices $=$ $\left.0.0011, \mathrm{p}_{\text {obs<exp }}=0.9996, \mathrm{p}_{\text {obs }>\exp }=0.0004\right)$.

\section{Niche overlap analysis}

Null model analyses of niche overlap among species showed nearly the same patterns during both seasons: there was random habitat resource partitioning according to RA2, but a non-random concentrated use of specific 
(A)

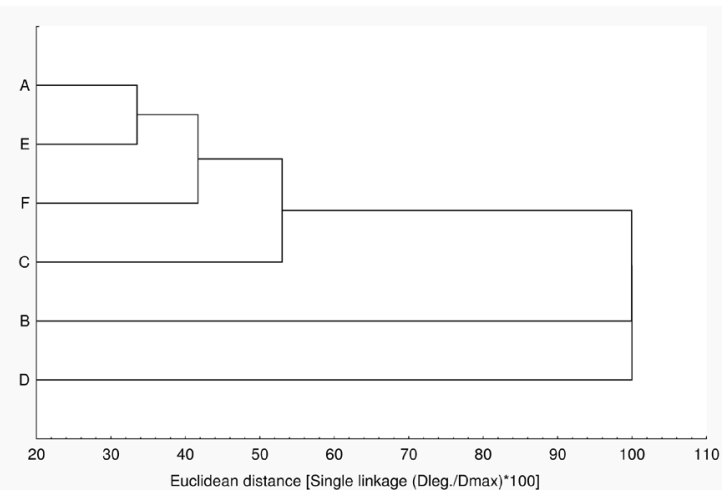

(C)

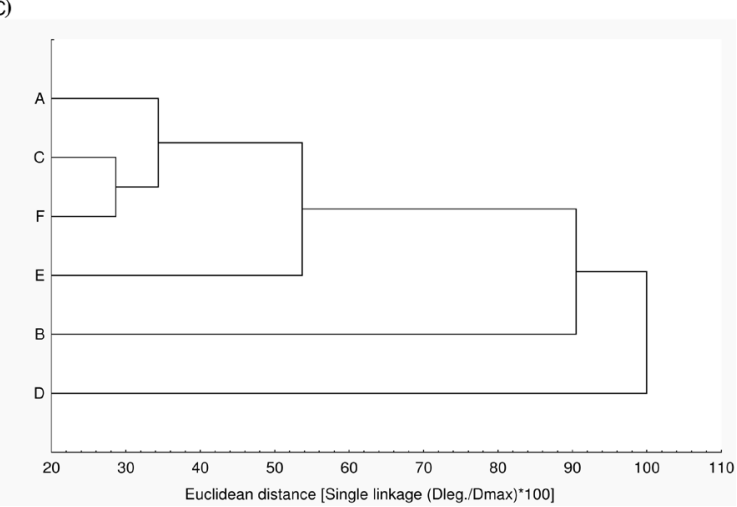

(B)

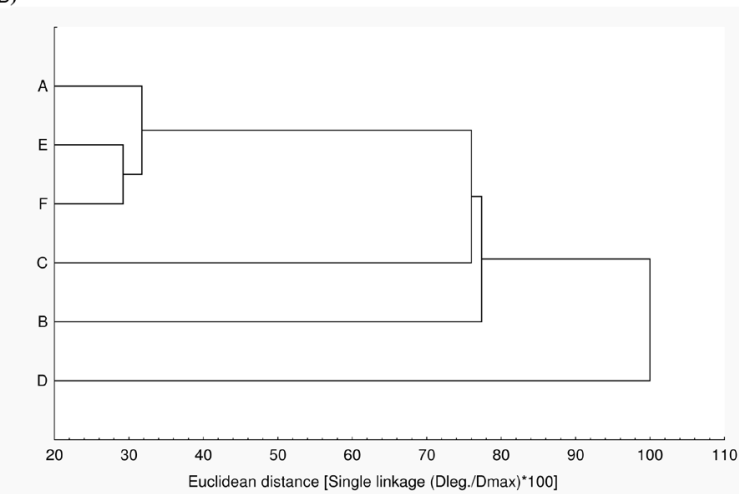

Fig. 1. UPGMA dendrogram showing the dissimilarities among habitat types based on amphibian species composition. (A) wet and dry seasons cumulated, (B) only wet season, (C) only dry season.

habitat types by several species according to RA3 (Table 3). Closer inspection of the dataset (Table 1) revealed that this concentration of species with high relative abundance occurred in habitat $\mathrm{D}$, and especially in the wet season (note the different level of significance of $\mathrm{p}_{\text {obsexp }}$ between seasons, Table 3 ).

Table 2. Results of paired t-test for determining the significance of interseasonal differences in the relative abundance of the various amphibian species by habitat type. Significant values are reported in boldface. DF = degrees of freedom.

\begin{tabular}{llll}
\hline Habitat type & $\begin{array}{l}\text { t-value } \\
\text { (paired t-test) }\end{array}$ & DF & $\mathrm{p}$ \\
\hline $\mathrm{A}$ & -2.83 & 23 & $\mathbf{0 . 0 1 0}$ \\
$\mathrm{B}$ & -1.78 & 23 & 0.088 \\
$\mathrm{C}$ & -2.63 & 23 & $\mathbf{0 . 0 1 5}$ \\
$\mathrm{D}$ & -2.70 & 23 & $\mathbf{0 . 0 1 3}$ \\
$\mathrm{E}$ & 0.92 & 23 & 0.368 \\
$\mathrm{~F}$ & 1.73 & 23 & 0.098 \\
\hline
\end{tabular}

\section{Species clustering}

UPGMA cluster analysis showed some interseasonal differences in species clustering (Fig. 2). During the wet season, three close clusters were formed: 1 ) a group formed by Bufo (Amietophrynus) regularis, Bufo (Amietophrynus) steindachneri and Ptychadena porosissima; 2) a group formed by Bufo (Amietophrynus) vittatus, Xenopus laevis, Leptopelis bocagii, and Ptychadena anchietae and 3) a group formed by Phrynobatrachus acridoides, Phrynobatrachus dendrobates, and Ptychadena oxyrhynchus (Fig. 2A). On the other hand, during the dry season only two close clusters were formed: 1) a group formed by two species, i.e. Bufo regularis and Ptychadena porosissima and 2) a group formed by Phrynobatrachus dendrobates, Ptychadena oxyrhynchus, Kassina senegalensis and Leptopelis bocagii (Fig. 2B).

\section{Discussion}

\section{Community organization}

Previous diversity analyses showed that the amphibian fauna of Lake Nabugabo accounts for about $28 \%$ of the 
(A)

Afrixalus fulvovit

Hyper. cinnam.

Hyper. viridiflavus

Bufo regularis

Bufo steindacneri

Ptychadena poris. Bufo vittatus

Xenopus laevis

Leptopelis bocagei

Ptychadena anch.

Phrynob. acridoides

Ptychadena oxhyr.

Phrynob. dendrobates

Hylarana galamensis

Afrana angolensis

Phrynob. natalensis

Kassina senegalensis

Hylarana albolabris

Ptychadena mascar.

Phrynob. graueri

Hoplob. occipitalis

Hyper. bayoni

Hyper. kivuensis

Hyper. nasutus

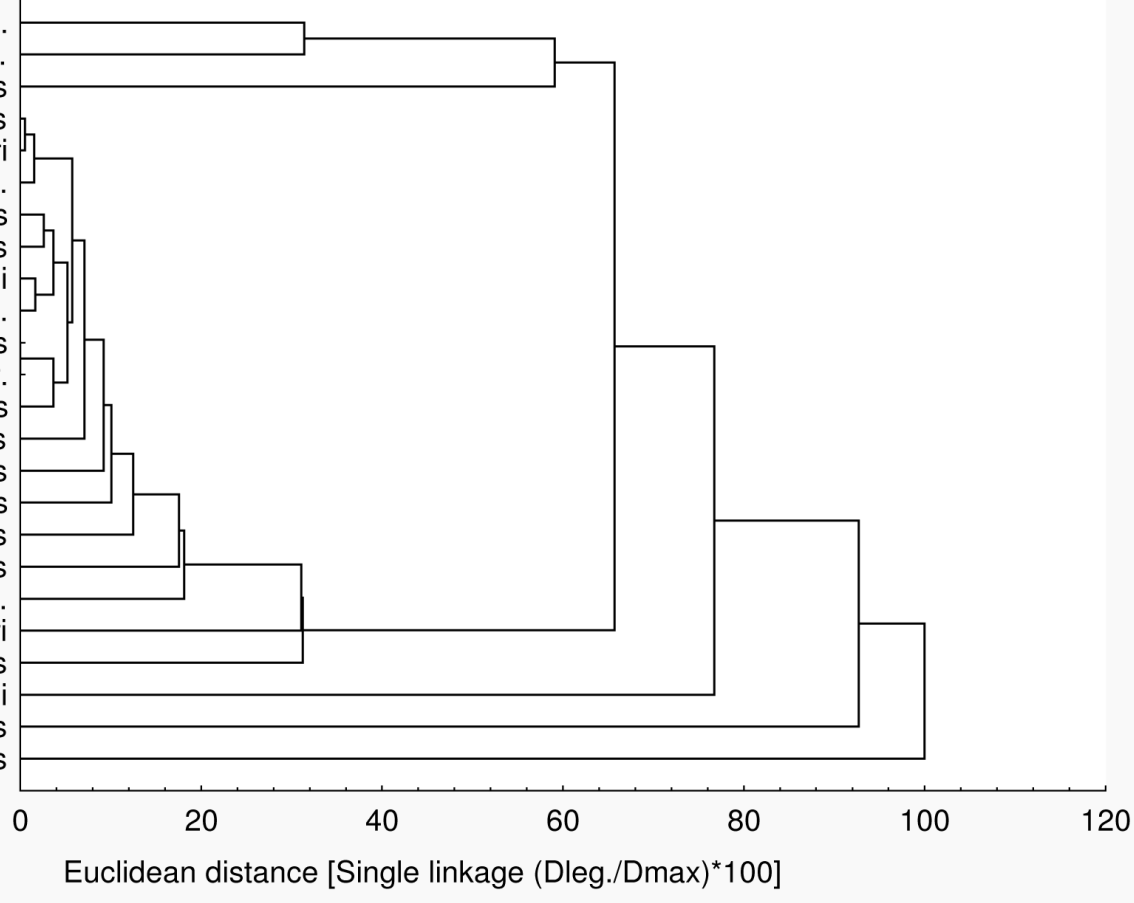

(B)

Afrixalus fulvov

Hyper. cinnamo.

Bufo regularis

Ptychadena poris.

Bufo steindachneri

Bufo vittatus

Phrynob. acridoides

Phrynob. dendrobates

Ptychadena oxhyr.

Kassina senegal.

Leptopelis bocagei

Xenopus laevis

Hylarana galamensis

Phrynob. natalensis

Afrana angolensis

Phrynob. graueri

Ptychadena anch.

Ptychadena mascar.

Hylarana albolabris

Hoplob. occipitalis

Hyper. viridiflavus Hyper. bayon

Hyper. kivuensis

Hyper. nasutus

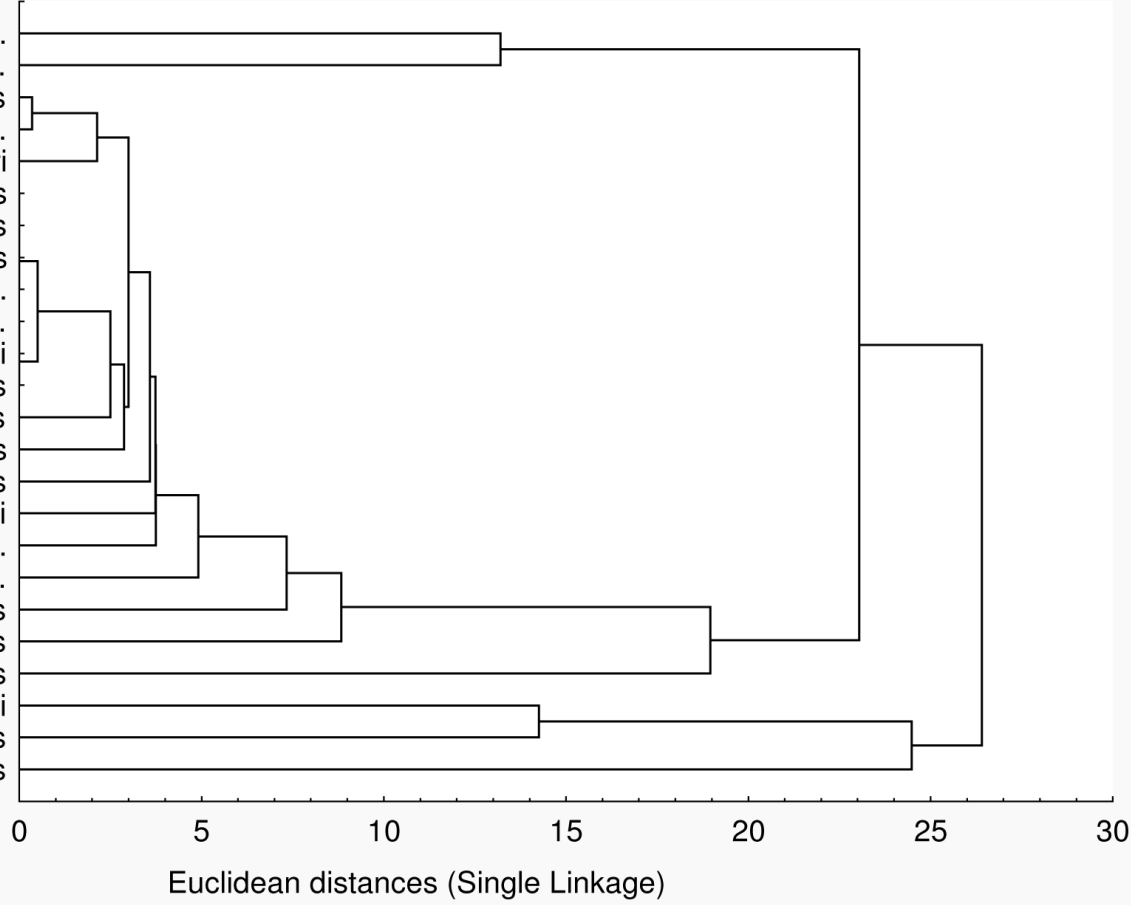

Fig. 2. UPGMA dendrogram showing the dissimilarities among amphibian species based on their presence/absence in the six habitat types, during the wet season (A) and during the dry season (B). 
Table 3. Niche overlap analysis with null models for the studied community of amphibians, during the wet season and during the dry season. Two randomization algorithms (RA2 and RA3) of Lawlor (1980) were used for this analysis with 30000 Monte Carlo permutations.

\begin{tabular}{lllllllll}
\hline & $\begin{array}{l}\text { Mean observed } \\
\text { overlap }\end{array}$ & $\begin{array}{l}\text { Observed } \\
\text { variance }\end{array}$ & $\begin{array}{l}\text { Mean of } \\
\text { simulated } \\
\text { indices }\end{array}$ & $\begin{array}{l}\text { Mean of } \\
\text { simulated } \\
\text { variances }\end{array}$ & $\begin{array}{l}\text { Variance of } \\
\text { simulated } \\
\text { indices }\end{array}$ & $\begin{array}{l}\text { Variance of } \\
\text { simulated } \\
\text { variances }\end{array}$ & $\mathrm{p}_{\text {obsexp }}$ & $\mathrm{p}_{\text {obs>exp }}$ \\
\hline RA2 & 0.365 & 0.130 & 0.363 & 0.112 & 0.00044 & 0.00004 & 0.519 & 0.480 \\
RA3 & 0.365 & 0.130 & 0.296 & 0.105 & 0.00036 & 0.00005 & 0.995 & 0.0005 \\
RA2 & 0.357 & 0.124 & 0.373 & 0.105 & 0.00046 & 0.00005 & 0.230 & 0.770 \\
RA3 & 0.357 & 0.124 & 0.313 & 0.100 & 0.00042 & 0.00004 & 0.964 & 0.036 \\
\hline
\end{tabular}

total number of amphibian species recorded up to now in Uganda (Behangana and Arusi 2004), with five families being represented, i.e. Ranidae (8 species), Petropedetidae (4 species), Hyperoliidae (8 species), Bufonidae (3 species) and Pipidae (1 species). The fact that this community represents a relatively conspicuous portion of the amphibian fauna of a wide tropical region makes the present study particularly interesting in order to elucidate assembly patterns of tropical amphibians in general.

Our Monte Carlo analyses clearly indicated that Lake Nabugabo amphibian community was non-randomly structured along the habitat niche dimension, with simulated C-scores being significantly greater than observed ones in all seasons. As this pattern could not be produced by chance (Gotelli and Graves 1996, Gotelli and Entsminger 2003), this suggests that there may be a potential for a competitively structured organization of the Lake Nabugabo amphibians (Gotelli and Graves 1996, Gotelli 2000, Friggens and Brown 2005).

When non-random community organization is uncovered, this pattern may often depend on resource partitioning patterns by species in order to minimize interspecific competition (Pianka 1973, Gotelli 2000, Gotelli and Entsminger 2003, Luiselli 2006a, 2008b, 2008c). However, the pattern of habitat-type partitioning observed in Lake Nabugabo amphibians does not necessarily imply that it was dependent on competition but simply that it is not a product of chance. Indeed, checkerboard patterns are sometimes generated by habitat affinities rather than by competition (Gotelli and McCabe 2002). We therefore explored this issue even further by null models of niche overlap estimates between pairs of species. Both randomization algorithms (RA2 and RA3) rejected the hypothesis of a competitively structured community of species in each season and even when seasons were pooled. Instead, one of the two algorithms (RA3) was able to detect a non-random concentration of species showing high relative abundance in given habitat types, particularly in the swamp forest during the wet season. Thus, the comparative evidence of 1) non-random community structure according to C-score analysis, 2) absence of resource partitioning according to niche overlap null models analysis, and 3) non-random concentration in given habitat types according to RA3, led us to think that community organization in Lake Nabugabo amphibians is generated by habitat affinities rather than by interspecific competition (Gotelli and McCabe 2002).

Previous studies supported the idea that phylogeny may have a strong role on community niche structure (Vitt et al. 1999).

\section{Seasonal patterns}

We also detected a strong effect of the season on the dataset structure. This is verified by a few concurrent points of evidence. Firstly, as already mentioned, our Monte Carlo methods detected a non-random concentration of highly abundant species in the swamp forest habitat especially during the wet season (with the same pattern being marginally significant during the dry season). We consider this pattern being dependent on that high numbers of amphibians tend to concentrate around inundated swamps for feeding and reproduction, as seasonally inundated forests are sometimes amongst the most productive habitats in the world (Molles et al. 1998) with the huge nutrient input occurring during food pulses supporting large numbers of invertebrates and other prey animals that in turn serve as the base for these highly productive ecosystems (Ross and Baker 1983, Turner et al. 1994, Ostfeld and Keesing 2000). The occurrence of an unlimited food resource supply after flooding may be the cause for the non-random concentration of amphibians found in swamp forest during the wet season. These aggregations of amphibians in flooded forests may constitute relevant concentration points also for a suite of higher-level predators, e.g. for snakes (Luiselli 2006b). It is, however, noteworthy that the highest species richness was observed in the Eragrostis-Loudetia vegetation zone (17 species vs 14 species in the swamp forest, Behangana and Arusi 2004), 
although the relative abundance of species appeared less than in swamp forest.

Secondly, in our UPGMA analyses the amphibians were grouped into an higher number of clusters during the wet season than during the dry season. This pattern is not easy to interpret because 1) the knowledge on the ecology of the various species is minimal (Channing and Howell 2006), and 2) we lack data to present any analysis that would show a separation of ecological groups, for instance established species-trait matrices deriving some measure that would delineate functional groups. We suppose that a combination of resource partitioning patterns and species-specific habitat preferences (specialization) could be the main reasons for trends in the formation of clusters in the UPGMA analyses. The medium altitude in evergreen forest with mature tall trees and open understory, the shore line - composed of sandy beaches and scanty vegetation and the Cyperus papyrus zone - usually composed of pure stands of papyrus with hardly any other vegetation and underlain by water, tend to be inhabited by the least number of species which tend to be specialized because these habitats are limited in terms of food resources and hiding sites from predators (Behangana unpubl.). The hierarchical formation of clusters when the wet and dry seasons are combined shows a tendency towards habitats specialization with the Cyperus papyrus and shoreline zones being the most closely linked and specialized sites overall. During the wet season, favorable conditions (for feeding, breeding, hiding from predators) are readily available in most habitats, allowing most species to spread far and wide to exploit these conditions (thus most habitats clustering at a higher similarity distance during the wet season). The Cyperus papyrus zone together with the medium altitude evergreen forest cluster together forming the most highly specialized zones during the wet season, and are thereafter joined by the shoreline zone. The Eragrostis-Laudatia zone together with the medium altitude evergreen forest cluster together during the dry season, and are then joined by the shoreline as zones with highly specialized species. Species in these habitats have to put up with an increase human activity during this season that include cattle grazing and in the worst cases, burning (Behangana et al. unpubl.).

Thirdly, there were interseasonal differences in the relative abundance of the various amphibian species in three out of six habitat types, and in all cases the higher abundances were received during the wet season. This trend corroborates other studies on herpetofaunas from tropical Africa showing remarkably higher biomasses during the rainy months (Barbault 1976, 1977, 1987, 1991, Akani et al. 2004, Luiselli 2006b, Garner et al. 2007).

However, it should be remarked that, since there are only 24 species in the entire assemblage, the absence of only a few, say one or two species, e.g. during dry season would significantly alter the clusters, even though ecologically speaking, the change in composition may not be significant. But either way, within the dendrograms both habitats $\mathrm{E}$ and $\mathrm{C}$ are part of one larger cluster in both seasons, whereas it is habitats $\mathrm{B}$ and $\mathrm{D}$ that are constantly separated. The changes may be due to seasonal effects but could just as well be collecting artifacts.

\section{Conclusions}

Our study has conveyed information in order to answer to the three key-questions posed in the Introduction. First, the amphibian assemblage at Lake Nabugabo showed a clear non-random structure; second, there were evident seasonal variations on the community composition and species clustering; third, habitat affinities were likely important in shaping the nonrandom structure of the amphibian assemblage under study. Further studies are however needed to verify these patterns with other Afrotropical amphibian communities.

\section{References}

Akani, G. C. et al. 1999. Snake communities of moist forest and derived savanna sites of Nigeria: biodiversity patterns and conservation priorities. - Biodiv. Conserv. 8: 629-642.

Akani, G. C. et al. 2004. Amphibians recorded in forest swamp areas of the River Niger Delta (southeastern Nigeria), and the effects of habitat alteration from oil industry development on species richness and diversity. - Appl. Herpetol. 2: $1-22$.

Barbault, R. 1976. Etude quantitative des peuplements d'Amphibiens et des Reptiles d'une savane arbustive de la region de Bouake (Côte-d'Ivoire): densites et cycles saisonniers d'abundance. - Ann. Univ. Abidjan Ser. E9: 143-152.

Barbault, R. 1977. Structure et dynamique d'une herpetocenose de savane (Lamto, Côte-d'Ivoire). - Geol. Ecol. Trop. 1: 309-334.

Barbault, R. 1987. Pression de predation et evolution des strategies demographiques en zone tropicale: le cas des lezards et des amphibiens. - Rev. Zool. Afr. 101: 301-327.

Barbault, R. 1991. Ecological constraints and community dynamics: linking community patterns to organismal ecology. The case of tropical herpetofaunas. - Acta Oecol. 12: 139-163.

Behangana, M. and Arusi, J. 2004. The distribution and diversity of amphibian fauna of Lake Nabugabo and surrounding areas. - Afr. J. Ecol. 42 (suppl 1): 6-13.

Bury, R. B. and Corn, P. S. 1991. Sampling methods for amphibians in streams in the Pacific northwest. General technical report. - Pacific Northwest Res. Station, Portland, Oregon.

Channing, A. and Howell, K. M. 2006. Amphibians of east Africa. - Edition Chimaira.

Chase, J. M. and Leibold, M. A. 2003. Ecological niches: linking classical and contemporary approaches. - Univ. of Chicago Press.

Digby, P. G. N. and Kempton, R. A. 1987. Multivariate analysis of ecological communities. - Chapman and Hall.

Duellmann, W. E. 2005. Cuzco Amazonico: the lives of amphibians and reptiles in an Amazonian rainforest. - Cornell Univ. Press. 
Ernst, R. and Rödel, M.-O. 2005. Anthropogenically induced changes of predictability in tropical anuran assemblages. Ecology 86: 3111-3118.

Ernst, R. and Rödel, M.-O. 2006. Community assembly and structure of tropical leaf-litter anurans. - Ecotropica 12: 113-129.

Ernst, R. and Rödel, M.-O. 2008. Patterns of community composition in two tropical tree frog assemblages: separating spatial structure and environmental effects in disturbed and undisturbed forests. - J. Trop. Ecol. 24: 111-120.

Filippi, E. and Luiselli, L. 2007. Non-random seasonal variation in the structure of a Mediterranean snake community. - Web Ecol. 7: 40-46.

Friggens, M. H. and Brown, J. H. 2005. Niche partitioning in the cestode communities of two elasmobranches. - Oikos 108: 76-84.

Gardner, T. A. et al. 2007. Spatial and temporal patterns of abundance and diversity of an east African leaf litter amphibian fauna. - Biotropica 39: 105-113.

Gotelli, N. J. 2000. Null model analysis of species co-occurrence patterns. - Ecology 81: 2606-2621.

Gotelli, N. J. and Entsminger, E. J. 2003. EcoSim: null model software for ecology. - Acquired Intelligence, New York.

Gotelli, N. J. and Graves, G. R. 1996. Null models in ecology. Smithsonian Inst. Press.

Gotelli, N. J. and McCabe, D. J. 2002. Species co-occurrence: a meta-analysis of J. M. Diamond's assembly rule. - Ecology 83: 2091-2096.

Gotelli, N. J. and McGill, B. J. 2006. Null versus neutral models: what's the difference? - Ecography 29: 793-800.

Lamotte, M. 1998. Le mont Nimba. Réserve de la biosphère et site du patrimoine mondial (Guinée et Cote d' Ivoire). UNESCO Publishing.

Lawlor, L. R. 1980. Structure and stability in natural and randomly constructed competitive communities. - Am. Nat. 116: 394-408.

Lawton, J. H. 1999. Are there general laws in ecology? - Oikos 84: 177-192.

Lehsten, V. and Harmand, P. 2006. Null models or species co-occurrence patterns: assessing bias and minimum iteration number for the sequential swap. - Ecography 29: 786-792.

Luiselli, L. 2006a. Resource partitioning and interspecific competition in snakes: the search for general geographical and guild patterns. - Oikos 114: 193-211.

Luiselli, L. 2006b. Interspecific relationships between two species of sympatric Afrotropical water snake in relation to a seasonally fluctuating food resource. - J. Trop. Ecol. 22: 91-100.

Luiselli, L. 2008a. Community ecology of African reptiles: historical perspective and a meta-analysis using null models. Afr. J. Ecol. 46: 384-394.
Luiselli, L. 2008b. Do lizards communities partition the trophic niche? A worldwide meta-analysis using null models. - Oikos 117: 321-330.

Luiselli, L. 2008c. Resource partitioning in freshwater turtle communities: a null model meta-analysis of available data. - Acta Oecol. 34: 80-88.

Luiselli, L. and Akani, G. C. 2002. An investigation into the composition, complexity and functioning of snake communities in the mangroves of south-eastern Nigeria. - Afr. J. Ecol. 40: 220-227.

Molles, M. C. et al. 1998. Managed flooding for riparian ecosystem restoration. - Bioscience 48: 749-756.

Ostfeld, R. S. and Keesing, F. 2000. Pulsed resources and community dynamics of consumers in terrestrial ecosystems. Trends Ecol. Evol. 15: 232-237.

Parris, K. M. 2004. Environmental and spatial variables influence the composition of frog assemblages in sub-tropical eastern Australia. - Ecography 27: 392-400.

Pianka, E. R. 1966. Latitudinal gradients in species diversity: a review of the concepts. - Am. Nat. 100: 33-46.

Pianka, E. R. 1973. The structure of lizard communities. - Ann. Rev. Ecol. Syst. 4: 53-74.

Pickersgill, M. 2007. Frog search. - Edition Chimaira.

Rödel, M. O. et al. 2004. The amphibians of south-eastern Republic of Guinea (Amphibia: Gymnophiona, Anura). - Herpetozoa 17: 99-118.

Rohde, K. 1992. Latitudinal gradients in species diversity: the search for the primary cause. - Oikos 65: 514-527.

Ross, S. T. and Baker, J. A. 1983. The response of fishes to periodic spring floods in a southeastern stream. - Am. Midl. Nat. 109: 1-14.

Scheiner, S. M. and Willig, M. R. 2007. A general theory of ecology. - Theor. Ecol. 1: 1-8.

Schiotz, A. 1999. Treefrogs of Africa. - Edition Chimaira.

Simberloff, D. 2004. Community ecology: is it time to move on? - Am. Nat. 163: 787-799.

Smith, E. P. and Zaret, T. M. 1982. Bias in estimating niche overlap. - Ecology 63: 1248 -1253.

Sneath, P. A. and Sokal, R. 1973. Numerical taxonomy: the principles and practice of numerical classification. - Freeman.

Stone, L. and Roberts, A. 1990. The checkerboard score and species distributions. - Oecologia 85: 74-79.

Toft, C. A. 1985. Resource partitioning in amphibians and reptiles. - Copeia 1985: 1-21.

Turchin, P. 2001. Does population ecology have general laws? Oikos 94: 17-26.

Turner, T. F. et al. 1994. Temporal and spatial dynamics of larval and juvenile fish abundance in a temperate floodplain river. - Copeia 1994: 174-183.

Vitt, L. J. et al. 1999. Historical ecology of Amazonian lizards: implications for community ecology. - Oikos 87: 286-294. 